\title{
PENGARUH AROMATERAPI LEMON (CITRUS) TERHADAP PENURUNAN NYERI MENSTRUASI PADA MAHASISWI PROGRAM STUDI ILMU KEPERAWATAN FAKULTAS KEDOKTERAN UNIVERSITAS SAM RATULANGI MANADO
}

\author{
Sefty Rompas \\ Lenny Gannika
Program Studi Ilmu Keperawatan Fakultas Kedokteran
Universitas Sam Ratulangi \\ Email : seftirompas@yahoo.com
}

\begin{abstract}
The Aromatherapy of orange (Citrus) is one of the relaxation measures to reduce dismenore, also improves mood and reduces anger. Limeone is one of the ingredients of The orange aromatherapy's oil which can inhibit the prostaglandin so it can reduce dismenore. The purpose of this study is to know The Influence of Orange's aromatherapy against dismenore in Sam Ratulangi University's Nursing Students, Manado. Design of this study is using a pre-experimental one-group-pre-test-post-test-design. Sampel of this study consisted of 26 respondents with the sampling method using a non probability sampling with saturation sampling technique. The results of this study using the Wilcoxon Signed Rank Test at a significance level of $95 \%$, obtained that the value $\rho-0,000$, value is smaller than the significant value of 0.05. Conclution in this study there is influence of Orange's aromatherapy (Citrus) on decrease dismenore in Sam Ratulangi University's Nursing Students, Manado
\end{abstract}

Keywords: Aromatherapy,Lemon,Dismenore

Abstrak : Aromaterapi lemon (Citrus) merupakan salah satu relaksasi untuk menurunkan nyeri menstruasi. Aromaterapi lemon juga meningkatkan mood dan mengurangi rasa marah. Limeone merupakan salah satu kandungan minyak aromaterapi lemon yang dapat menghambat sistem kerja prostaglandin sehingga dapat mengurangi nyeri. Tujuan penelitian ini adalah mengetahui pengaruh Aromaterapi Lemon (Citrus) terhadap Penurunan Nyeri Menstruasi pada mahasiswi Program Studi Ilmu Keperawatan Fakultas Kedokteran Universitas Sam Ratulangi Manado. Rancangan Menggunakan pre eksperimen one-grouppre-test-post-test-design. Sampel terdiri dari 26 responden dengan metode pengambilan sampel menggunakan pendekatan non probability sampling dengan teknik saturation sampling. Hasil menggunakan uji Wilcoxon Signed Rank Test pada tingkat kemaknaan 95\%, didapatkan nilai $\rho$ - Value 0,000 lebih kecil dari nilai signifikan 0,05. Kesimpulan ada pengaruh aromaterapi lemon (Citrus) terhadap Penurunan nyeri menstruasi pada mahasiswi Ilmu Keperawatan Fakultas Kedokteran Universitas Sam Ratulangi Manado.

Kata Kunci : Aromaterapi, lemon, Nyeri Menstruasi 


\section{PENDAHULUAN}

Menstruasi merupakan suatu proses berkala yang datang setiap 28-30 hari. Masa menstruasi pertama (menarche) biasanya dimulai pada usia 11-15 tahun. Siklus tersebut akan berlanjut hingga tiba masa menopouse, kecuali jika terjadi kehamilan. Pada setiap masa menstruasi, darah menstruasi yang berwarna merah gelap akan dikeluarkan setiap bulan dan berlangsung selama 3-8 hari (Rasjidi, 2013).

Perubahan yang biasa dihadapi wanita saat mengalami mestruasi yaitu cemas, stress, depresi dan biasanya di dampingi dengan gejala kejang-kejang menstruasi atau bahasa medisnya dysmenorrea (Sukarni \& Wahyu, 2013). Nyeri menstruasi terjadi terutama di perut bagian bawah, tetapi dapat menyebar hingga ke punggung bagian bawah, pinggang, panggul, paha atas, hingga betis. Nyeri juga bisa disertai kram perut yang parah. Kram tersebut berasal dari kontraksi otot rahim yang sangat intens saat mengeluarkan darah menstruasi dari dalam rahim (Sinaga, et al., 2017). Nyeri merupakan sensasi yang rumit, unik, universal dan bersifat individual. Dikatakan bersifat individual karena respon individu terhadap sensasi nyeri beragam dan tidak bisa disamakan satu dengan lainnya (Asmadi, 2008).Dengan adanya nyeri menstruasi wanita biasa merasa malas untuk bergerak, badan menjadi mudah lelah, lemas dan pingsan. Dampak negatif yang didapat antara lain pekerjaan tertunda, malas ke sekolah, tugas menumpuk dan nilai akademis menurun (Novarenta, 2013)

Angka kejadian nyeri menstruasi di dunia rata-rata lebih dari 50\%. Di indonesia angka kejadian prevalensi nyeri menstruasi berkisar 55\% di kalangan usia produktif. Di amerika serikat, klien dan litt melaporkan prevalensi dismenore mencapai 59,7\% dan di sewedia sekitar $72 \%$. Angka kejadian nyeri menstruas berkisar $45-95 \%$ dikalangan wanita usia produktif dengan upaya penanganan dismenore dilakukan $51,2 \%$ dengan terapi obat, $24,7 \%$ dengan relaksasi dan $24,1 \%$ dengan distraksi atau pengalihan nyeri (Depkes RI , 2010 ; Azizah, 2014)

Manajemen nyeri atau pain management merupakan salah satu bagian dari disiplin ilmu medis yang menggunakan pendekatan multidisiplin yang termasuk didalammnya pendekatan farmakologikal (termasuk pain modifiers), non farmakologikal dan psikologikal dalam upaya menghilangkan nyeri atau pain relief. Manajemen nyeri non farmakologikal merupakan upaya mengatasi atau menghilangkan nyeri dengan menggunakan pendekatan non farmakologi. Upaya tersebut antara lain relaksasi, distraksi, massage, guided imaginarydan lain sebagainya (Syamsiah, 2015).

Penatalaksanaan dalam menurunkan nyeri menstruasi dengan relaksasi yaitu menggunakan aromaterapi lemon. Aromaterapi lemon untuk meningkatkan mood dan mengurangi rasa marah (Iryani, 2015). Minyak aromaterapi lemon mempunyai kandungan limeone 6680, geranil asetat, netrol, terpine 6-14\%, $\alpha$ pinene 1-4\% dan mrcyne (Young, 2011 ; Suwanti 2018). Limeone adalah komponen utama dalam senyawa kimia jeruk yang dapat menghambat sistem kerja prostaglandin sehingga dapat mengurangi nyeri (Namazi, et al., 2014).Prostaglandin merangsang penekanan otot (tonus), kontraksi otot rahim, dan penekanan pembuluh darah (vasopresi) rahim yang menyebabkan nyeri iskemik dan keluhan nyeri menstruasi (Suharmiati \& Lestari, 2005). Prostaglandin juga mempengaruhi kontaktilitas otot polos dan modulasi aktivitas hormonal. Prostaglandin dapat terlibat dalam kondisi patologi diantrannya infertilitas pria, dismenore, status hipertensi, pre-eklamsia-eklamsia, dan syok anafilatik(Bobak, Lowdermilk \& Jensen. 2012).

Berdasarkan jumlah mahasiswi keperawatan di Program Studi Ilmu 
Keperawatan Fakultas Kedokteran Universitas Sam Ratulangi manado yang berjumlah 264 ditemukan bahwa 260 mahasiswi yang biasa mengalami nyeri menstruasi. Hasil pengkajian melalui wawancara yang diwakili 20 mahasiswi, didapatkan bahwa 3 mahasiswi mengalami nyeri ringan, 6 mahasiswi nyeri sedang dan 11 mahasiswi nyeri berat. Cara penanganan nyeri menstruasi yang biasa dilakukan oleh mahasiswi yaitu 16 mahasiswi dengan cara tidur, 2 mahasiswi menggunakan obat paracetamol atau ampisilin, 1 dengan kompres air hangat dan 1 mahasiswi meninggikan kaki saat berbaring. Menurut mahasiswi dari 4 cara penanganan untuk menghilangkan nyeri ini 2 cara yang dapat meredahkan nyeri yaitu menggunakan obat paracetamol atau ampisilin dan kompres air hangat. Alasan beberapa mahasiswi tidak mencari cara penanganan nyeri menstruasi ini adalah karena mereka menganggap nyeri menstruasi sudah biasa dirasakan namun mereka mengakui jika nyeri menstruasi ini sangat menganggu mereka saat kegiatan belajar mengajar dan persiapan dalam nenghadapi tes ujian.Berdasarkan uraian diatas maka penulis tertarik untuk melakukan penelitian di bidang ini dengan judul: Pengaruh Aromaterapi Lemon (Citrus) terhadap Penurunan Nyeri Menstruasi.

\section{METODE PENELITIAN}

Penelitian ini menggunakan rancangan pre eksperimen (one-group-pre-test-post-testdesign) (Setiadi, 2013)Penelitian ini dilakukan di Program Studi Ilmu Keperawatan Fakultas Kedokteran Universitas Sam Ratulangi Manado. Penelitian ini dilaksanakan pada September - Desember 2018. Populasi dari penelitian ini berjumlah 264. Teknik pengambilan sampel menggunakan pendekatan non probability sampling (sampling jenuh).Penentuan jumlah sampel dalam peneliti ini memakai perhitungan dari Arikunto. Dengan jumlah sampel 26. Yang telah memenuhi kriteria inklusi :Mahasiswi yang bersedia menjadi responden, Mahasiswa yang sedang menstruasi, Skala nyeri menstruasi 4 sampai 6 sedang, Mahasiswi yang masih aktif kuliah di Program Studi Ilmu Keperawatan Fakultas Kedokteran Universitas Sam Ratulangi Manado, Tidak menggunakan aromaterapi lain.

Penelitian ini menggunakan instrument Numerik Rating Scale. Peneliti memasukkan skala intensitas nyeri dengan rentang skala nyeri $0-10: 0=$ Tidak nyeri, 1-3 = Nyeri ringan, $4-6=$ Nyeri sedang,7-9 $=$ Nyeri berat, $10=$ Tak tertahankan. Instrument yang digunakan untuk pemberian aromaterapi antara lain Kassa, Aromaterapi essential oil lemon $10 \mathrm{ml}$, Pipet tetes/spuit, SOP (Standar Oprasional Prosedur) Prosedur penatalaksanaan saat pemberian aromaterapi lemon disusun bersadarkan pembahasan yang ada dalam tinjauan teori.

Data yang mendukung dalam penelitian ini yaitu data primer dan data sekunder.Data primer pada penelitian ini yaitu melalui intervensi langsung kepada mahasiswi yang ada di Program Studi Ilmu Keperawatan Fakultas Kedokteran Universitas Sam Ratulangi Manado.Data sekunder pada penelitian ini yaitu melalui data dari petugas bagian akademik Program Studi Ilmu Keperawatan Fakultas Kedokteran Universitas Sam Ratulangi Manado.Analisa data penelitian menggunakan Wilcoxon Signed Rank TestTingkat kemaknaan yang digunakan dalam penelitian ini yaitu $95 \%(\alpha 0,05)$.

\section{HASIL dan PEMBAHASAN}

Tabel 1. Distribusi Data Responden Berdasarkan Umur

\begin{tabular}{ccc}
\hline Umur & $\mathbf{n}$ & $\mathbf{\%}$ \\
\hline 17 Tahun & 5 & 19,2 \\
18 Tahun & 3 & 11,5 \\
19 Tahun & 5 & 19,2 \\
20 Tahun & 7 & 26,9 \\
21 Tahun & 4 & 15,4 \\
22 Tahun & 2 & 7,7 \\
\hline Total & 26 & 100.0 \\
\hline
\end{tabular}

Sumber : Data Primer, 2018 
Hasil yang didapatkan dari tabel 1 rentang usia responden adalah 17-22 tahun yang dikategorikan menjadi remaja dan dewasa. Sesuai dengan hasil pengukuran bahwa responden terbanyak yang didapatkan memiliki usia 20 tahun atau 26,9\%. Menurut Dian (2016) secara umum putaran masa kehidupan manusia dibagi dalam 5 fase, dalam 5 fase ini masa remaja (13-22 tahun) dan masa dewasa (22-55 tahun).

Tabel 2.Frekuensi Skala Nyeri Responden Sebelum

\begin{tabular}{ccc}
\hline Skala & \multicolumn{2}{c}{ Pretest } \\
\cline { 2 - 3 } Nyeri & $\mathrm{n}$ & $\%$ \\
\hline $4-6$ & 26 & 100 \\
\hline Total & 26 & 100.0 \\
\hline
\end{tabular}

Sumber : Data Primer, 2018

Hasil penelitian dari tabel 2 menunjukan bahwa nyeri menstruasi sebelum dilakukan tindakan pemberian aromaterapi lemon kepada 26 responden didapatkan nyeri sedang 4-6 (100\%) dengan standar deviasi 0,744 . Hasil penelitian ini sejalan dengan hasil penelitian Suwanti, et al., (2018) yang berjudul pengaruh aromaterapi lemon (cytrus) terhadap penurunan nyeri menstruasi sebelum diberikan aromaterapi lemon adalah mean 4,95, median 5 standar deviasi 1,146 dengan skala nyeri rendah 2 dan tertinggi 6 . Menurut Asmadi (2008)Nyeri yang berdasarkan berat ringannya antara lain nyeri ringan yaitu nyeri dengan intensitas rendah, nyeri sedang yaitu nyeri yang menimbulkan reaksi, nyeri berat yaitu nyeri dengan intensitas yang tinggi. Seseorang yang mengalami nyeri sebelumnya dan dapat mengatasi nyeri yang tepat maka dapat mengatasi nyeri yang dirasakan selanjutnya (Potter \& Perry, 2005).

Tabel 3. Skala Nyeri Responden Sesudah

\begin{tabular}{ccc}
\hline Skala & \multicolumn{2}{c}{ Posttest } \\
\cline { 2 - 3 } Nyeri & $\mathrm{n}$ & $\%$ \\
\hline $1-3$ & 23 & 88,5 \\
$4-6$ & 3 & 11,5 \\
\hline Total & 26 & 100.0
\end{tabular}

Sumber : Data Primer, 2018
Hasil penelitian dari tabel 3 menunjukan bahwa nyeri menstruasi sesudah dilakukan tindakan pemberian aromaterapi kepada 26 responden terdapat perubahan skala nyeri terbanyak pada skala nyeri ringan dengan jumlah 23 orang atau $88,5 \%$ dan yang tidak ada perubahan 3 orang atau $11,5 \%$ dengan nilai standar deviasi 0,796. .Penelitian ini sejalan dengan penelitian yang dilakukan oleh Cholifah Sidoarjo (2016), menyatakan bahwa Pemberian aromaterapi inhalasi lemon lebih efektif menurunkan nyeri persalinan kala I fase aktif daripada diberikan bimbingan nafas dalam. Aromaterapi inhalasi lemon dapat menurunkan nyeri persalinan kala I fase aktif. Kecemasan mempengaruhi penurunan nyeri persalinan.

Tabel 4.Hasil Analisis Pretest-Posttest

\begin{tabular}{cccc}
\hline Waktu & Mean & SD & p-value \\
\hline Pretest & 5,08 & 0,744 & \multirow{2}{*}{0,000} \\
Posttest & 2,82 & 0,796 & \\
\hline
\end{tabular}

Sumber : Data Primer, 2018

Berdasarkan Tabel 4 hasil uji statistik dengan menggunakan uji wilcoxon signed rank test dapat dikatakan bahwa Ho ditolak atau ada pengaruh skala nyeri sebelum dan sesudah pemberian aromaterapi lemon pada mahasiswi yang sedang mengalami nyeri menstruasi. Penelitian ini sejalan dengan penelitian yang dilakukan oleh Kurniawati Magelang (2016) penggunaan aromaterapi lemon dilakukan melalui inhalasi dengan cara memberikan aromaterapi di atas kassa/tisu sejumlah 3 tetes dengan pipet tetes/spuit, kemudian dihirupkan kepada responden. Pemberian minyak aromaterapi lemon diberikan selama 15 menit dan dilakukan 2 kali dalam sehari selama 2 hari menemukan bahwa terdapat penurunan rata-rata skala nyeri post caesarea sebelum dan setelah diberikan aromaterapi lemon pada hari ke-0 dan hari ke-1 post sectio caesarea selisih antara sebelum dan setelah diberikan aromaterapi lemon pada hari ke 0 adalah 1,70 pada tindakan pertama 1,80 
pada tindakan kedua dengan $\rho=0,000$. Hal ini berarti nilai $(\rho<0,05 ; \alpha=0,05)$ yang menunjukan bahwa ada perbedaan yang signifikan antara sebelum dan setelah diberikan aromaterapi lemon.

\section{SIMPULAN}

Berdasarkan hasil penelitian dan juga pembahasan tentang pemberian aromaterapi lemon (citrus) ditemukan bahwa nyeri menstruasi sebelum diberikan aromaterapi lemon (citrus) skala sedang (4-6), nyeri menstruasi setelah diberikan aromaterapi lemon (citrus) skala ringan (13 ), terdapat pengaruh yang signifikan antara aromaterapi lemon terhadap penurunan nyeri menstruasi sebelum dan sesudah diberikan aromaterapi lemon (citrus).

\section{DAFTAR PUSTAKA}

Asmadi. ( 2008 ), Konsep Dasar Keperawatan, Jakarta : EGC

Asmadi. (2008), Teknik Prosedural Keperawatan Konsep dan Aplikasi Kebutuhan Dasar Klien. Jakarta. Selemba Medika.

Azizah, N. (2014). Aplikasi Relaksasi Nafas Dalam Sebagai Upaya Penurunan Skala Nyeri Menstruasi (Dismenorrhea) Pada Siswi Mts. Ibtidaul Falah Samirejo Dawe Kudus Tahun 2013. Jurnal Ilmu Keperawatan dan Kebidanan, 5(1).

KurniawatiA, D., Setyowati E, Rahayu, H., \& Wijayanti, K. (2016). Akupresur Efektif Mengatasi Intensitas Nyeri Post Sectio Caesarea.

Bobak, I, M., Lowdermilk, L, D., \& Jensen, D, M. (2012). Buku Ajar Keperawaan Maternitas. Buku Kedokteran EGC.

Cholifah, S., Raden, A., \& Ismarwati, I. (2016). Pengaruh aromaterapi inhalasi lemon terhadap penurunan nyeri persalinan kala I fase aktif. Jurnal Kebidanan dan Keperawatan Aisyiyah, 12(1), 46-53.

Dian. (2016). Masa Lalu, Masa Kini, Masa Depan. Jakarta. Elex Media Komputindo

Iryani, N. (2015). 365 ideas of happiness. E-book. Mirzan Digital Publishing.

Novarenta, A. (2013). Guided Imagery Untuk Mengurangi Rasa Nyeri Saat Menstruasi. Jurnal Ilmiah Psikologi Terapan, l(2), 179-190.

Namaziet al. (2014). Nanocrystalline cellulose acetate (NCCA)/graphene oxide (GO) nanocomposites with enhanced mechanical properties and barrier against water vapor. Cellulose, 21(5), 3527-3539.

Potter, A \& Perry, G, A. (2005). Buku Ajar Fundamental Keperawatan: Konsep, Proses dan Praktek, Vol 1, E/4. Buku Kedokteran EGC.

Sukarni, I \& Wahyu, P. (2013). Buku Ajar Keperawatan Maternitas, Yogyakarta: Nuha Medika

Setiadi. (2013). Konsep dan Praktek Penulisan Riset Keperawatan. Edisi 2. Yogyakarta. Graha Ilmu.

Sinaga, et al. (2017). Manajemen Kesehatan Maternitas. Universitas Nasional: IWWASH Global One

Suharmiati, \& Lestari, H. (2005). Ramuan Tradisional untuk Keadaan Darurat di Rumah. Tangerang. Agromedia Pustaka.Sukarni, I \& Wahyu, P. (2013). Buku Ajar Keperawatan Maternitas, Yogyakarta: Nuha Medika

Suwanti, et al. (2018). Pengaruh Aromaterapi Lemon (Cytrus) Terhadap Penurunan Nyeri Menstruasi pada Mahasiswi di Universitas Respati Yogyakarta. Jurnal Keperawatan Respati Yogyakarta, 5(1), 345-349 
eJournal Keperawatan (e-Kp) Volume 7 Nomor 1, 15 Februari 2019

Suyanto, Susila., \& Siswanto. (2016). Metodologi Penelitian Kesehatan dan Kedokteran. Yogyakarta. Bursa Ilmu.

Syamsiah, N., \& Muslihat, E. (2015). Pengaruh terapi relaksasi autogenik terhadap tingkat nyeri akut pada pasien abdominal pain Di IGD RSUD Karawang 2014. KEPERAWATAN, 3(1).

Rasjidi, I. (2013). Panduan kehamilan muslimah. Jakarta Selatan:Mizan Digital Publishing

Yati, A \& Anggi, P. (2016). Seksualitas dan Kesehatan Reproduksi Perempuan. Rajawali Pers. 